\title{
Marine migrations in anadromous brown trout (Salmo trutta). Fjord residency as a possible alternative in the continuum of migration to the open sea
}

Del Villar, Diego; Aarestrup, Kim; Skov, Christian; Koed, Anders

Published in:

Ecology of Freshwater Fish

Link to article, DOI:

10.1111/eff.12110

Publication date:

2014

Link back to DTU Orbit

Citation (APA):

Del Villar, D., Aarestrup, K., Skov, C., \& Koed, A. (2014). Marine migrations in anadromous brown trout (Salmo trutta). Fjord residency as a possible alternative in the continuum of migration to the open sea. Ecology of Freshwater Fish, 23(4), 594-603. https://doi.org/10.1111/eff.12110

\section{General rights}

Copyright and moral rights for the publications made accessible in the public portal are retained by the authors and/or other copyright owners and it is a condition of accessing publications that users recognise and abide by the legal requirements associated with these rights.

- Users may download and print one copy of any publication from the public portal for the purpose of private study or research.

- You may not further distribute the material or use it for any profit-making activity or commercial gain

- You may freely distribute the URL identifying the publication in the public portal 


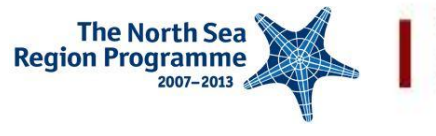

DTU Aqua

National Institute of Aquatic Resources

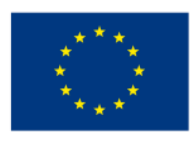

http://www.northsearegion.eu/ivb/home/ www.aqua.dtu.dk

\title{
Marine migrations in anadromous brown trout (Salmo trutta). Fjord residency as a possible alternative in the continuum of migration to the open sea
}

\author{
Diego del Villar-Guerra*, Kim Aarestrup, Christian Skov and Anders Koed.
}

Technical University of Denmark, National Institute of Aquatic Sciences, Vejlsøvej 39; 8600; Silkeborg, Denmark.

\begin{abstract}
Partial migration is a common phenomenon in many fish species. Trout (Salmo trutta) is a partially migratory species where some part of the population migrate to the marine environment, while another remains in freshwater.

In the years 2008 and 2009, a total of 159 wild sea trout smolts were tagged with acoustic and PIT tags in the river Villestrup (Denmark) to study the initial post-smolt marine behaviour within a fjord system. We found that the strategies of the sea migrants vary: some stay in the fjord while others migrate to the sea suggesting that partial migration occurs even in the marine environments.

Overall, a total of $53 \%$ of the tagged smolts migrated from the fjord to the sea, and $47 \%$ stayed (or potentially died) in the fjord. The ratios of fjord-resident vs. sea-migrating post-smolts were consistent at the study times and no differences between the early and late migration periods of the smolts were observed. The individual's size or body condition at the time of tagging did not affect survival or the migratory decisions in the fjord. High overall initial survival (74\%) was found 30 days after the fjord entry. We suggest that within a continuum of migration to sea, there is a migratory decision point when sea trout post-smolts encounter a fjord system. At this point, post-smolts will assess the possibility of migration versus the alternative of fjord residency.
\end{abstract}

Keywords: Telemetry, Partial migration, Live history strategies, Sea trout, Marine, Fjord

* Corresponding author: ddvi@aqua.dtu.dk

Article first published online: 18 Nov 2013

Please note that this is an author-produced PostPrint of the final peer-review corrected article accepted for publication. The definitive publisher-authenticated version can be accesses here:

http://dx.doi.org/10.1111/eff.12110 @ 1999-2013 John Wiley \& Sons, Inc 
Marine migrations in anadromous brown trout (Salmo trutta). Fjord residency as a possible alternative in the continuum of migration to the open sea.

Diego del Villar-Guerra*, Kim Aarestrup, Christian Skov and Anders Koed.

Technical University of Denmark, National Institute of Aquatic Sciences, Denmark.

Address: Vejlsøvej 39; 8600; Silkeborg. Denmark.

Email: ddvi@aqua.dtu.dk.

Keywords: Telemetry, Partial migration, Live history strategies, Sea trout, Marine, Fjord.

\begin{abstract}
Partial migration is a common phenomenon in many fish species. Trout (Salmo trutta) is a partially migratory species where some part of the population migrate to the marine environment, while another remains in freshwater.
\end{abstract}


In the years 2008 and 2009, a total of 159 wild sea trout smolts were tagged with acoustic and PIT tags in the river Villestrup (Denmark) to study the initial post-smolt marine behaviour within a fjord system. We found that the strategies of the sea migrants vary: some stay in the fjord while others migrate to the sea suggesting that partial migration occurs even in the marine environments.

Overall, a total of $53 \%$ of the tagged smolts migrated from the fjord to the sea, and $47 \%$ stayed (or potentially died) in the fjord. The ratios of fjord-resident vs. sea-migrating post-smolts were consistent at the study times and no differences between the early and late migration periods of the smolts were observed. The individual's size or body condition at the time of tagging did not affect survival or the migratory decisions in the fjord. High overall initial survival (74\%) was found 30 days after the fjord entry. We suggest that within a continuum of migration to sea, there is a migratory decision point when sea trout post-smolts encounter a fjord system. At this point, post-smolts will assess the possibility of migration versus the alternative of fjord residency.

\section{Introduction}

Fish migration is the individual's behavioural response to the interactions between external factors (environment, temperature, etc.) and factors concerning the individual's internal status (fear, hunger, etc.) (Lucas and Baras et al., 2001). Partial migration is a phenomenon where a population is composed of both migratory and resident individuals (Chapman et al., 2012, Hendry et al., 2004, Jonsson and Jonsson 1993). Partial migration in fishes is seen as an adaptive response to a changeable 
environment, and the ultimate goal is to increase individual fitness and population persistence (Cucherousset et al., 2005).

Studies assessing the physiological basis of partial migration in salmonids indicate that factors such as body condition (e.g. Fulton's K; Fulton 1902) and the individual's energetic reserves may influence the individual's decision towards migration (Forseth et al., 1999, Jonsson and Gravem 1985, Jonsson et al., 2001, Wysujack et al., 2009). In addition, the ratio mortality to growth is believed to be a selective driver in this decision and ultimately be the cause of such migration (e.g. Brönmark et al., 2008). As a general statement, fish will maximize their individual fitness by moving to the areas where this ratio is minimized (Gross 1987).

Partial migrations are observed in trout (Salmo trutta L.) populations, with sea trout individuals performing repeated seasonal movements between freshwater and the sea (Elliott 1994, Klemetsen et al., 2003). This behaviour is referred to as non-breeding partial migration in Chapman et al., (2012). Thus migrants and residents share breeding habitat but spend the non-breeding season apart. The alternation of habitats observed in trout (both within the freshwater habitat and between freshwater, the estuary and the sea) has been associated to their degree of life history variation (Klemetsen et al., 2003).

While partial migration processes in salmonids are documented between freshwater and the marine environment (Hendry et al., 2004, Klemetsen et al., 2003), there is little information about the migratory patterns in the marine environments where the fish spend a large part of their life cycle. This lack of knowledge is strongly related to technical and methodological constraints in gathering 
reliable behavioural data. Hence, the marine environment is considered a priority area for sea trout research (Drenner et al., 2012).

By employing telemetry (acoustic and PIT-tags) for two consecutive years and tracking a high number of individuals ( $n=159)$ over a long period, this study explores the migratory behaviour of wild sea trout post-smolts, while negotiating a fjord system towards the sea.

Since the ultimate goal of migrating to the sea most likely is to improve fitness (e.g. by increasing growth), it can be hypothesized that in some cases it should be advantageous for the sea trout postsmolts to reside in the fjords or estuaries' for shorter or longer periods of time before moving to the open sea or returning to the river. This depends on the trade-off between food availability and mortality risk.

Indeed, variation in stop over time in the fjords and estuaries has been reported. Two different telemetry studies looking at the migration patterns of wild sea trout post-smolts in a Norwegian fjord systems (Finstad et al., 2005, Thorstad et al., 2007), show that the all the sea trout post-smolts resided in the inner, and occasionally the middle parts of fjord, for the duration of the study (two months). Conversely, Moore and Potter (1994) describe the behaviour of wild sea trout smolts through a river estuary in UK where residence within the estuary normally last less than a tidal cycle, and the majority of fish migrate through the estuary on a single ebb tide (Moore and Potter 1994). These few studies suggest that there is a difference between rivers in the dispersal of trout. i.e., some populations may migrate to the sea, while another may stay in the fjord. 
The primary aim of our study was to investigate the marine behaviour of wild sea trout post smolts in a fjord system. In particular, we examine the migratory decisions fish undertake during their fjord stay within the continuum of migratory possibilities. It was hypothesized that in addition to the migratory decisions fish make in the riverine environments, there is an additional decision making point when the fish enter the saline environment (fjord): to continue migration to the sea (Sea migrants, SMs), or stay in the fjord (Fjord residents, FRs).

Furthermore, this study aimed to identify potential effects on the post-smolts migration to the sea. In particular, 1) by studying the role of the seasonality in the adoption of a specific migratory tactic and 2) assessing the effects of body size (length and weight) and condition (Fulton's K) on the migratory decisions in the fjord.

The marine phase is a critical stage for post-smolts. It is in these areas where high mortalities are likely (Thorstad et al., 2012). Among others, the adaptation to the new marine environment and the existence of new predators are believed to cause this loss (Jepsen et al., 2006, Koed et al., 2006, Thorstad et al., 2007).

The final aim of the study was to assess the initial survival and the return rates of post-smolts, in order to evaluate their relationships with the migratory decisions in the fjord.

\section{Material and Methods}




\section{Study site}

Mariager fjord on the east coast of Jutland, Denmark (Fig. 1) is characterized as a sill fjord with a relatively low water exchange with the adjacent system, the Kattegat Sea. Mariager fjord is the longest fjord in Denmark with a length of approximately $48 \mathrm{~km}$ and is $2-4 \mathrm{~km}$ wide with a total catchment area of approximately $572 \mathrm{~km}^{2}$ and a volume of 235 mill. $\mathrm{m}^{3}$ (Fallesen et al., 2000, Olesen 2001).The fjord has the highest recorded primary production among the coastal systems surrounding Denmark (Kaas et al., 1996).

The physiographic of the fjord is complex and can be principally divided in three parts: the outer, the middle and the inner fjord. The outer part of the fjord (25 km in length) consists of tidal plains with water depths of around $1 \mathrm{~m}$, except for a narrow $6 \mathrm{~m}$ deep channel maintained by dredging and held open to the Kattegat by the tide. The inner and middle parts ( $23 \mathrm{~km}$ in length) have depths of up to 30 meters and are permanently anoxic below $15 \mathrm{~m}$ (Fallesen et al., 2000). This configuration restricts bottom-water exchange with the Kattegat Sea.

The fjord is micro-tidal with a tidal range of only $20-30 \mathrm{~cm}$. Salinity values vary between $12-25 \%$ and the fjord is characterized as brackish. The input of freshwater is about 161 mill. $\mathrm{m}^{3} \mathrm{y}^{-1}$ corresponding to $5 \mathrm{~m}^{3} \mathrm{~s}^{-1}$, representing one third of the water in Mariager fjord. The river Villestrup (mean annual discharge $1.1 \mathrm{~m}^{3} \mathrm{~s}^{-1}$ ) is the major freshwater source for Mariager fjord and also constitutes the most important sea trout tributary running into the fjord. Another tributary, the river Kastbjerg (mean annual discharge $0.5 \mathrm{~m}^{3} \mathrm{~s}^{-1}$ ), also holds a sea trout population, as well as several other smaller tributaries to the fjord. 


\section{Smolt trapping and tracking}

The present study was carried out over two years (2008 and 2009) between the months of AprilAugust in 2008 and April-July in 2009. A total of $n=159$ descending wild sea trout smolts from the Villestrup river were trapped and tagged in late April (24 April - 25 April) and mid-May (13 May - 20 May) for both years.

The migrating smolts were captured in a full covering Wolf-type trap placed approximately $300 \mathrm{~m}$ from the river outlet and in connection with a weir at a fish farm (See fig.1; Site 1). Phenotypic smolt characteristics: silvery body colour, absence of parr marks, darkened fins and stream lined body shape were used as indicators of migrating smolts (Aarestrup et al., 2000). Sea trout smolts over $16 \mathrm{~cm}$ were selected to minimize the effects of tagging on the individual's behaviour (Jepsen et al., 2002). Sex determination was not possible without killing the individuals for the examination, and hence this information is not included in this experiment.

The sea trout smolts were double tagged with individual coded, acoustic transmitters (Thelma $7.3 \mathrm{~mm}$ smolt transmitter, Thelma Biotel AS, Postboks 6170, Sluppen 7435 Trondheim) and passive integrated transponders (PIT-tags) (Texas Instruments, RI-TRP-RRHP, half duplex, 134 kHz, length $23.1 \mathrm{~mm}$, diameter $3.85 \mathrm{~mm}$ and weight $0.6 \mathrm{~g}$ (air), 00800-ASK-TEXAS).

The acoustic transmitters had a guaranteed battery life of 80 days with a delay of 20-60 seconds between consecutive transmissions. 
The surgical implantation method described in Aarestrup et al., (1999) was used to implant the tags. An experienced fish surgeon performed surgical implants in accordance to the guidelines described in permission (2012-DY-2934-00007) from the Danish Experimental Animal Committee. The fish was anesthetized with benzocaine ( $25 \mathrm{mg} / \mathrm{L}$, Sigma Chemical Co., St Louis, USA) until operculum rate was slow and irregular (2-4 per min). Then the fish was placed on a V-shaped surgical table and the transmitters were inserted into the body cavity through a mid-ventral incision, posterior to the pelvic girdle. The incision was closed with two separate sutures. The duration of the operation ranged between 1 and $2 \mathrm{~min}$ and the tagged individual recovered in 4 to 6 minutes after the operation. The tagged smolts were later released downstream of the PIT-tag antennae and trap approximately $150 \mathrm{~m}$ from the river outlet (See fig. 1; Site 1).

To study migration patterns in different parts of the Mariager fjord an array of 14 acoustic listening stations (ALS) (VR2, VEMCO Ltd, Canada) were deployed at five sites along the fjord (See fig. 1).The ALS were continuously in operation during the period of this experiment.

The position of the ALS stations throughout the fjord enabled monitoring tagged fish entering the fjord, residing or exiting the fjord to the Kattegat Sea. The distribution of the ALS divided the fjord into three compartments: the Inner fjord: within site 2, and between site 2 and 3; the Middle fjord: between sites 3 and 4; and the Outer fjord: between sites 4 and 5 (See fig 1.)

Ranges of each ALS varied between 130 and 400 m during range tests. The width of the river or fjord varied between 100 and $900 \mathrm{~m}$ at the ALS sites. Dependent of the signal receiver conditions between one and five ALS were moored at each station. One ALS was moored in the mouth of the river 
Villestrup and a maximum of five ALS were deployed where the maximum width of the fjord was observed (Site 2).

When a transmitter is detected on an ALS, the transmitters' code, date and time of the detection were stored.

To detect any return of acoustic tagged (and PIT-tagged) individuals into the riverine environment, PIT-antennae stations (PIT-stations) were placed 200-300m upstream from the river mouths of the Villestrup and Kastbjerg rivers. A system consisted of two circular swim-trough antennas situated 10 $\mathrm{m}$ apart and connected to stationary data-logging transponder readers operating at $125 \mathrm{KHz}$ (model

TIRIS S- 2000, Texas Instruments). The readers logged individually numbered PIT-tags passing through the antenna loops and log date, time and the PIT-tag identification number. The two-antenna design allowed the discrimination of between up and downstream movements. Further descriptions of the antennae system can be found in (Svendsen et al., 2007). The PIT-tags antennae were continuously in operation from the beginning of the experiment until September 2012 (approximately 3 years after the last fish were tagged).

\section{Data analysis}

Two different tagging periods (April and May) were selected in this study to assess the role of the seasonality in the migration of post-smolts. This procedure was repeated for two consecutive years (2008-09). 
The movements of the post-smolts within the fjord were analysed in the inner (within site 2, and between site 2 and 3), middle (between sites 3 and 4), and outer parts (between sites 4 and 5), as delimited by the ALS. Fish last registered at station 5 were assumed to exit the fjord to the Kattegat Sea (See fig. 1).

The incidence of the fjord residents in the zones were studied during the months of May, June, and July to look for preferences in post-smolts' habitat use. In these months similar numbers of postsmolts were recorded within the fjord for both years. This approach allows comparisons to be made between the months and the years.

The body size (length and weight) and body condition were examined to look for differences between the smolts trapped and tagged at different tagging periods. Body condition was calculated as follows (1):

$$
\mathrm{K}=100\left(\frac{W}{L^{3}}\right)
$$

where weight (W) is expressed in grams, and total length (L) in centimetres (Fulton 1902).

In the analysis of the proximate causes of partial migration the individual's body condition, the month and the year of tagging were used as explanatory variables to explain the variability in the numbers of fish staying in the fjord (FR) versus the sea migrants (SM).

The analysis of the survival rates were conducted up to 30 days after entering the fjord. The initial survival was calculated as(2): 
Survial $_{\text {(Initial) }}=\frac{\mathrm{N}_{(\text {out })}<30 \mathrm{~d}+\mathrm{N}_{(\text {in })} \geq 30 \mathrm{~d}}{\mathrm{~N}_{(\text {total) }}}$

(2)

Where, $\mathrm{N}$ (out) $<30 \mathrm{~d}$ corresponds to the number of fish out of the fjord during the period of 30 days and $\mathrm{N}(\mathrm{in}) \geq 30 \mathrm{~d}$ is the number of fish detected inside the fjord at day 30 or later. $\mathrm{N}$ (total) refers to the total number of fish that entered the fjord. Individual single registrations at any of the ALS were used as evidence of post-smolt survival.

Differences in survival were tested across the months and years. Furthermore, the individual's size (length or weight) and body condition ( $k$ ) was contrasted against the post-smolts survival to see if they had any effect on their survival.

Finally, the return rate of post-smolts was calculated as the percentage of fish registered at PIT-tags antennae in the freshwater streams when returning from the marine migration. This approach gives a minimal measure of the marine survival since some sea trout individuals may stray to other steams or lose the PIT-tags.

\section{Statistical testing}

The statistical tests used in this experiment were selected according to the characteristics of the dependent variable (i.e. continuous, counts, etc.). The assumptions of the models were tested prior the analysis (i.e. independence of the variables, normality, homoscedasticity and over dispersion). 
The One-way Anova test was used to look for differences in length, weight and body condition of the study animals in relation to the time the fish was tagged and their survival.

The Chi-square test was used to analyse the proportions of fjord residents (FR) and sea migrants (SM) FR and SM between the tagging periods. Later, this test was used to analyze the incidence of FR in different parts of the fjord at different times. Ultimately, the Chi-square test was used to look for differences in the survival rates.

The Two-way ANOVA test was used in order to examine if body conditions (Fulton's K) at the time of tagging were related to the month and the year fish were tagged. Additionally, the logistic regression was performed to see if the probability of FR vs SM was related to the individual's body condition, month and year of tagging. All the variables were included in the model at the same time since it provides the relationships between the variables without requesting the best predictors.

All statistical analyses were performed in SPSS (version 20.0).

\section{Results}

\section{Smolt trapping and tracking}

In 2008, a total of 79 sea trout smolts were trapped and tagged in the $24^{\text {th }} \& 25^{\text {th }}$ of April ( $\left.n=40\right)$, and $19^{\text {th }} \& 20^{\text {th }}$ of May $(n=39)$. In 2009 , a total of 80 sea trout smolts were captured and tagged on the $15^{\text {th }}$ April $(n=40)$ and on the $13^{\text {th }} \& 18^{\text {th }}$ of May $(n=40)$. No differences in length or weight were observed between the tagging periods (One-way ANOVA, $p$ values $>0.05$ ) (Table 1 ). 
In the years 2008 and 2009, a total 144 out of 159 tagged smolts (90.6 \%) moved downstream and entered the fjord system right after being released ( $<24$ hours). The remaining 15 smolts $(9.4 \%)$ were never recorded at any of the ALS located in the fjord or in the PIT-tag antennae. This may be associated with predation by cormorants, heron and otter (all observed in the lower river), reluctance to migrate, and tag loss. These individuals were excluded from further analysis.

During the time of this experiment, two different groups of post-smolts were categorized. The first group consists of individuals last recorded at site 5 (See fig. 1). Those individuals were assumed to continue their migration in the Kattegat Sea (sea-migrants, SMs), since no individuals recorded at site 5 were later recorded at the inner arrays. The second group contains the individuals which were never recorded at site 5 , and were hence assumed to have died or stayed within the fjord during this time (fjord-residents, FRs).

The differences in the number of FR and SM across the years were not significantly different (Chisquare: $\chi^{2}{ }_{1}=0.046, p=0.482$ ). Overall, $46.5 \%$ of the fish entering the fjord stayed and $53.5 \%$ migrated out the fjord in both years (Table 2). Additionally, no statistical significant differences were found in the proportion of FR and SM between or within the tagging periods of April and May (Chi-square: $p$ values $>0.05)$.

The SM post-smolts followed a one-way route out of the river and fjord, with no individuals reversing their migratory direction. The migration to the open sea occurred rapidly and the vast majority $96.1 \%$ (74 out 77) of the SM left the fjord within the first 41 days after entering the fjord (mean \pm sd: $18.4 \pm$ 1.4 days; $n=77)$. The FR fish were mostly registered (76\% of the total FR detections) in the inner and 
middle parts of the fjord (Fig. 2). The FRs were recorded within the fjord up to 133 days after they entered the fjord (mean \pm sd: $60.1 \pm 39.6$ days; $n=67$ ).

The incidence of the FRs in the areas (Inner, Middle and Outer fjord) were significantly different within the same month (Chi-square: $\chi^{2}{ }_{1}=16.750, p<0.001$ ). However, no differences were observed across the months, nor within the same month across the years (Chi-square: $p$-values> 0.05 ).

\section{Effects of body condition on migration}

Overall, body conditions (Fulton's K) were higher in 2009 than in 2008 (Two-way ANOVA; F= 22.309, $d f=1, p=0.001 ;$ Table 1). Furthermore, individuals tagged in April had greater body condition than in May (Two-way ANOVA; $F=46953.361, d f=1, p=0.001 ;$ Table 1). This pattern was constant between

years as is indicated by the non-significant interaction month $\mathbf{x}$ year (Two-way ANOVA; $F=4.628, d f=1$, $p=0.33)$.

The logistic regression demonstrated that the probability of being an FR or SM was not related to the individual's body condition (Logistic regression: $W=0.237, d f=1, p=0.626$ ), month of tagging (Logistic regression: $W=0.083, d f=1, p=0.773$ ) or year (Logistic regression: $W=0.059, d f=1, p=0.808$ ).

\section{Survival}

Initial survival 
There was an overall high initial survival rate $(73.6 \%)$ which was observed in the post-smolts 30 days after the fjord entry (See table 2). The total survival rates observed in 2008 and 2009 were not significantly different (Chi-square: $\chi^{2}{ }_{1}=1.071, p=0.301$ ). However, the smolts tagged in April had a lower survival rate than those tagged in May (Chi-square: $\left.\chi^{2}=11.588, p<0.001\right)$. The survival rate of the post-smolts in the fjord was not affected by differences in body condition (k) or size (length or weight) at any of the studied periods (One-way ANOVA, $p$ values $>0.05$ ).

\section{Return rates}

None of the SM post-smolts were registered at the PIT-tag tag antennae in the rivers after they were last acoustically detected in the fjord. However, several FR were later registered in the rivers (See table 2).

The overall return rate to river was $6.2 \%$ (9 out of 144). This implies that $13.4 \%$ (9 out of 67 ) of FR post-smolts returned in both years. The FR tagged in 2008 returned in the months of January and February after 0.6 and 1.1 years in the marine. On the other hand, in 2009 the FR returned in the months of November and July after a minimum of 0.3 years, to a maximum 1.5 years at the marine. Additionally, a FR fish was recaptured by angling in the fjord 1.4 years after tagging.

\section{Discussion and Conclusion}


During the experiment two different migratory behavioural traits were observed: Sea trout post-smolt which stayed in the fjord for extended periods, up to 133 days (Fjord residents, FRs) and post-smolts leaving the fjord for the Kattegat Sea within 41 days after fjord entry (Sea migrants, SMs).

The large behavioral group of fjord residents is a new result since it differs from the general pattern of sea migrating post-smolts. This result opens up new possibilities in the continuum of partial migration beyond the fresh water phase. Our research suggests that besides the decision of smoltification in fresh water and the subsequent migration to sea, there could be a further decision making point after smolts enter the fjord, i.e., the fish are assessing the possibility of either sea migration or fjord residency.

Overall, a total of $47 \%$ of the tagged smolts stayed (or died) in the fjord and $53 \%$ exited in both years. The differences observed among the years and between or within the months were not statistically significant, implying that both migratory traits (FR and SM) were equally represented in the population of post-smolts at any of the studied periods.

The majority of SM post-smolts exited the fjord within the first 41 days. They followed a one-way route out with no individuals reversing their migratory direction. On the other hand, the FRs were mostly registered in the inner and middle parts of the fjord for extended periods (up to 133 days) and they were rarely present in the outer fjord.

This finding may imply that the decision to stay or leave the fjord is assessed and made shortly after the fjord entry. If the fish did not exit the fjord within the initial period of 41 days then the probabilities of sea migration were particularly low. This behaviour may be an adaptive trait, as quick 
decisions in the fjord may affect the fitness of individual fish in the fjord and at sea (i.e. a fast entry into the sea may improve survival or lessen competition for food sources).

The habitat used by the FRs (i.e. the inner and middle fjord) suggests that there is a certain degree of habitat selection within the fjord. It is believed that the physical characteristics of the outer fjord (narrow channel and tidal flats along the embankments) may not be a preferred habitat for FR postsmolts.

One could argue that the separation of FRs and SMs is a random event enhanced and maintained by the boundary barrier of the outer fjord. Thus, fish that leave the middle zone of the fjord can't stay in the outer fjord because of the unsuitability of this habitat and as a consequence they go to the sea. However, the remarkably consistent behaviour observed at any of the studied periods during two consecutive years suggests that this is an unlikely scenario to happen and two distinguishable postsmolts forms (i.e. FRs and SMs) are likely.

Because of the clear difference in behaviour between the FR and SM fish, we tentatively suggest that the fjord characteristics (e.g. food availability, low water exchange etc.) may be related to the migratory decisions in the fjord. There is a possibility that the entry of post-smolts in Mariager fjord may be analogous to lake entry of migrating parr in which the degree of anadromy varied according to the lake morphology due to its effect on growth and the relative number of available niches (Kristoffersen et al., 1994). It is believed that when smolts enter saline environments (i.e. the fjord), fish need to assess the cost of the open sea migration against the estuary residence alternative. 
According to other studies conducted in the nearby Northern Fjord Limfjorden (Denmark), the postsmolts diet in the fjord consists of: $46 \%$ Crustacean, $36 \%$ Fish, 10\% Insects and $7 \%$ Polychaete (Pedersen.S et al., 1995). These food items do not seem to differ from the sea trout food utilization in the Kattegat and Skagerrak Sea (Stål et al., 2006 and Knutsen et al., 2001). It is believed that if the food items in the fjord allow equivalent growth in the fjord as at sea then the post-smolts won't migrate to sea due to the high cost of this migration. More research is needed in this field in order to clarify whether sea trout diet and growth in the fjord can be compared to those at sea. This may shed light on potential cost-benefits of the fjord residency versus the migrating alternative.

Studies assessing the physiological basis of partial migration in salmonids indicate that body condition can affect the individual's decision of migration (Nielsen et al., 2004, Aarestrup et al., 2000). The results of this study show that even though fish tagged at different times did not differ in length or weight as separate variables, they had different body conditions (Fulton's K). The individuals tagged in April had better body conditions than individuals tagged in May. In spite of these differences, the proportion of FR versus SM was not affected by the individual's body condition, neither related with the month or year of tagging.

These results suggest that within the selected range of smolts sizes and weights, neither size nor condition were selective forces acting on the migration of post-smolts. The underlying causes of the present partial migrations are not elucidated by this experiment. However, in the context of a conditional strategy, it is possible that factors related to the energetic status (Forseth et al., 1999), growth and/or metabolic rate (Cucherousset et al., 2005), energy allocation (Jonsson and Jonsson 1998), and inherited components (Giger et al., 2006) might affect the individual's decision to 
migrated. We suggest further studies on the initial marine behaviour of sea trout incorporating measurements on the above mentioned factors to potentially identify proximate causes for the observed behaviour.

High overall initial survival rates (74\%) were found in the early stages of the post-smolts' marine run during the fjord stage. These results agree with a parallel study in Randers fjord where approximately $79 \%$ of the tagged wild sea trout post-smolts survived the marine migration through the fjord (Aarestrup et al., in press). However, the results are in contrast with other studies of salmonids suggesting high mortalities of post-smolts in the fjord stage (Thorstad et al., 2012).

The analyses of survival in this experiment reveal that individuals tagged in April had significantly lower initial survival rates than in May of both years. This result is unexpected since better body conditions were observed in April, thus a higher survival could be expected. Further analyses demonstrates that size (length and weight), and body condition of the tagged individuals were not related to the survival of post-smolts. It is possible that predation rates, difference in feeding opportunities, or different behaviours during the periods could be the causes of the observed differences in the post-smolt survival. Nevertheless, the same number of fish exited the fjord in April and May for both years.

The recordings received at the PIT-tag antennae showed that none of the sea migrating individuals were later registered in the upstream run as of September 2012 (three years after the last fish were tagged). This could suggest a possible evolutionary dead end in the case of all sea-migrating smolts dying during their marine stage. However, this is an unlikely scenario and we suggest that factors such 
as PIT-tag loss due to long sea-residency times, fish returning to a different stream or fishing mortality can provide a better explanation. For instance, in the present experiment $28.5 \%$ ( 2 out of 7 ) of the fish from 2009 which successfully returned to the rivers after the marine stage were registered in the upstream migration to the river Kastbjerg. The remaining fish were detected in their native stream of Villestrup. Fish which were detected in the river Kastbjerg were not recorded afterwards in their native stream. This result may indicate that the number of fish potentially straying into other rivers may be relatively high for the sea trout in the river Villestrup, as several more sea trout rivers exists in Mariager fjord and its surroundings.

Additionally, we speculate that the survival of the returning SM adults could be compromised by the fishing activities conducted both at sea, and in the fjord, since the use of nets is permitted in both those areas. The characteristics of the outer fjord, is a narrow channel with shoreline and the dikes, may provide fishermen with an easy access to deploy their nets in the main migratory pathways of sea trout. Sea trout staying in the inner and middle parts of the fjord are less vulnerable to the fishing activities due to the wider area giving better possibilities to escape net fishing. The local fishing inspectors have confirmed the existence of net fishing in the cited areas. However, at the moment there is not an official record of the number of sea trout caught. More research is crucial to confirm the causes and the magnitude of these losses. Future studies ought to assess the impact of fisheries on the return rate of sea-migrating adults.

Sea trout post-smolts which did not leave the fjord during the period of the acoustic battery life time (minimum of 80 days) survived and returned to the tributaries, probably to complete their life cycles. The returning rate of the FR post-smolts in the river was on average $13.4 \%$ in both years. This return 
rate is comparable to other studies of salmonids suggesting return rates in the natal rivers from $1 \%$ to $20 \%$ (Hvidsten et al., 2004). This percentage appears adequate to maintain the sea trout population in the river of origin as shown by Jonsson and Jonsson (2009). Furthermore, a fjord-resident fish recaptured in the fjord after approximately 1.4 years showed a growth of $2.4 \mathrm{~cm} \cdot \mathrm{month}{ }^{-1}$. This growth rate is comparable to the growth of the first-time sea migrants between 1 and 2 years at sea (Jonsson and Jonsson 2009), suggesting normal growth rates for the FR fish.

The FRs returned in a minimum of 0.6 to a maximum of 1.5 years after the fish entered in fjord as recorded by the PIT-tag antennae's. This result suggests that within first time migrants, $0+$ and $1+$ sea winter year classes are likely in River Villestrup. The limited numbers of FRs returning to the river make it unrealistic to extract any conclusions in relation to the seasonal patterns of this return.

In summary, the return rate in the studied post-smolts was higher for fish spending their marine period in the fjord compared with post-smolts migrating to sea. However, due to the uncertain fate of the SMs in this experiment, this finding cannot be interpreted in terms of the cost-benefits of partial migrations. More research is needed in order to clarify how the mortality to growth ratio is affecting the migratory decisions in the fjord.

The results of the present study suggest that if the conditions in the fjord allow high survival rates and comparable growth rates to the SMs, then post-smolts could increase relative individual fitness (enhanced growth leading to greater fecundity and/or enhanced survival) by staying in the fjord, and complete the marine phase without leaving the fjord. On the other hand, it could be speculated that 
fish migrating to the sea where high mortalities rates are likely, do so as there may be greater possibilities for feeding at sea, as opposed to in the fjord.

Overall, the diversification of migratory behavioural traits in the fjord (FR and SM) may lead to increased evolutionary fitness of the sea trout population in the river Villestrup, as indicated by Cucherousset et al., 2005. For instance, the migratory tactic could provide a selective advantage in fluctuating environments, especially when extremely changeable conditions appear. For example, in the autumn of 1997 the inner fjord became completely anoxic and sulphidic to the surface which resulted in a large number of fish deaths in the fjord, including sea trout individuals (Fallesen et al., 2000). Hence, in this case only sea trout that migrated to sea survived.

We advocate more studies on this life stage of brown trout including studies of fish otolith chemistry as indicated by Veniott et al., (2012) to finally confirm the existence of these two post-smolt forms (SM \& FR). Further, more studies on growth and survival of post-smolts at sea and in the fjord, are necessary to assess the cost-benefits of such migratory decisions. These potentially enable the elucidation of the ultimate and proximate mechanism of partial migration in the marine environments.

\section{Acknowledgements}

The research was funded by the Living North Sea project under the "Interreg IVB, North Sea Region Programme" funding mechanisms. Elements of the research were also funded by the Danish rod and net fish license funds and the strategic project SMOLTPRO, financed by the Swedish Research Council Formas. 
All methods applied were in agreement with current Danish regulations for the treatment and welfare of experimental animals.

\section{References}

Aarestrup, K., Jepsen, N., Rasmussen, G., and Okland, F. 1999. Movements of two strains of radio tagged Altlantic salmon, Salmo salar L., smolts through a reservoir. Fisheries Management and Ecology 6(2): 97-107.

Aarestrup, K., Nielsen, C., and Madsen, S.S. 2000. Relationship between gill Na+, K+-ATPase activity and downstream movement in domesticated and first-generation offspring of wild anadromous brown trout (Salmo trutta). Canadian Journal of Fisheries and Aquatic Sciences 57(10): 20862095.

Aarestrup, K., Baktoft, H., Koed, A., del Villar-Guerra., D. and Thorstad Eva B., in press. Comparison of the riverine and early marine migration behaviour and survival of wild and hatchery-reared sea trout (Salmo trutta) smolt. Marine Ecology Progress Series.

Brönmark, C., Skov, C., Brodersen, J., Nilsson, P.A., and Hansson, L.-A. 2008. Seasonal migration determined by a trade-off between predator avoidance and growth. PloS one 3(4): e1957.

Chapman, B., Skov, C., Hulthén, K., Brodersen, J., Nilsson, P., Hansson, L.A., and Brönmark, C. 2012. Partial migration in fishes: definitions, methodologies and taxonomic distribution. Journal of Fish Biology 81(2): 479-499. 
Cucherousset, J., Ombredane, D., Charles, K., Marchand, F., and Baglinière, J.L. 2005. A continuum of life history tactics in a brown trout (Salmo trutta) population. Canadian Journal of Fisheries and Aquatic Sciences 62(7): 1600-1610.

Drenner, S.M., Clark, T.D., Whitney, C.K., Martins, E.G., Cooke, S.J., and Hinch, S.G. 2012. A Synthesis of Tagging Studies Examining the Behaviour and Survival of Anadromous Salmonids in Marine Environments. PloS one 7(3): e31311.

Elliott, J.M. 1994. Quantitative ecology and the brown trout. Oxford University Press, USA.

Fallesen, G., Andersen, F., and Larsen, B. 2000. Life, death and revival of the hypertrophic Mariager Fjord, Denmark. Journal of Marine Systems 25(3): 313-321.

Finstad, B., $\varnothing$ kland, F., Thorstad, E.B., Bjørn, P.A., and McKinley, R.S. 2005. Migration of Atlantic salmon and sea trout post-smoltsin a Norwegian fjord system. Journal of Fish Biology 66: 86-96.

Forseth, T., Nesje, T.F., Jonsson, B., and Hårsaker, K. 1999. Juvenile migration in brown trout: a consequence of energetic state. Journal of Animal Ecology 68(4): 783-793.

Fulton, T.W. 1902. Rate of growth of sea fishes. Neill \& Company.

Giger, T., Excoffier, L., Day, P., Champigneulle, A., Hansen, M.M., Powell, R., and Largiadèr, C.R. 2006. Life history shapes gene expression in salmonids. Current biology: CB 16(8): R281.

Gross, M.R. 1987. Evolution of diadromy in fishes. American Fisheries Society Symposium, pp. 14-25. 
Hendry, A.P., Bohlin, T., Jonsson, B., and Berg, O.K. 2004. To sea or not to sea. Anadromy versus nonanadromy in salmonids. Oxford University Press, Oxford, UK.

Hvidsten, N.A., Johnsen, B.O., Jensen, A.J., Fiske, P., Ugedal, O., Thorstad, E.B., Jensås, J.G., Bakke, $\varnothing$. , and Forseth, T. 2004. Orkla - et nasjonalt referansevassdrag for studier av bestandsregulerende faktorer hos laks. Norwegian Institute for Nature Research Trondheim Jepsen, N., Koed, A., Thorstad, E.B., and Baras, E. 2002. Surgical implantation of telemetry transmitters in fish: how much have we learned? Hydrobiologia 483(1): 239-248.

Jepsen, N., Holthe, E., and $\varnothing$ kland, F. 2006. Observations of predation on salmon and trout smolts in a river mouth. Fisheries Management and Ecology 13(5): 341-343.

Jonsson, B., and Gravem, F.R. 1985. Use of space and food by resident and migrant brown trout, Salmo trutta. Environmental Biology of Fishes 14(4): 281-293.

Jonsson, B., and Jonsson, N. 1993. Partial migration: niche shift versus sexual maturation in fishes. Reviews in Fish Biology and Fisheries 3(4): 348-365.

Jonsson, N., and Jonsson, B. 1998. Body composition and energy allocation in life history stages of brown trout. Journal of Fish Biology 53(6): 1306-1316.

Jonsson, B., Jonsson, N., Brodtkorb, E., and Ingebrigtsen, P.J. 2001. Life history traits of Brown Trout vary with the size of small streams. Functional Ecology 15(3): 310-317. 
Jonsson, B., and Jonsson, N. 2009. Migratory timing, marine survival and growth of anadromous brown trout Salmo trutta in the River Imsa, Norway. Journal of Fish Biology 74(3): 621-638.

Kaas, H., Møhlenberg, F., Josefson, A., Rasmussen, B., Krause-Jensen, D., Jensen, H.S., Svendsen, L.M., Windolf, J., Middelboe, A.L., Sand-Jensen, K., and Pedersen, M.F. 1996. Danske fjordeStatus over miljøtilstand, årsagssammenhœnge og udvikling. . Danmarks Miljøundersøgelser.

Klemetsen, A., Amundsen, P.A., Dempson, J., Jonsson, B., Jonsson, N., O'connell, M., and Mortensen, E. 2003. Atlantic salmon Salmo salar L., brown trout Salmo trutta L. and Arctic charr Salvelinus alpinus (L.): a review of aspects of their life histories. Ecology of Freshwater Fish 12(1): 1-59.

Knutsen, J., Knutsen, H., Gjøsæter, J., and Jonsson, B. 2001. Food of anadromous brown trout at sea. Journal of Fish Biology 59(3): 533-543.

Koed, A., Baktoft, H., and Bak, B.D. 2006. Causes of mortality of Atlantic salmon (Salmo salar) and brown trout (Salmo trutta) smolts in a restored river and its estuary. River Research and Applications 22(1): 69-78.

Kristoffersen, K., Halvorsen, M., and Jørgensen, L. 1994. Influence of parr growth, lake morphology, and freshwater parasites on the degree of anadromy in different populations of Arctic char (Salvelinus alpinus) in northern Norway. Canadian Journal of Fisheries and Aquatic Sciences 51(6): 1229-1246.

Lucas, M.C. and Baras, E. 2001. Migration of freshwater fishes. Oxford: Blackwell Science Ltd. 
Moore, A., and Potter, E. 1994. The movement of wild sea trout, Salmo trutta L., smolts through a river estuary. Fisheries Management and Ecology 1(1): 1-14.

Nielsen, C., Aarestrup, K., Norum, U., and Madsen, S.S. 2004. Future migratory behaviour predicted from premigratory levels of gill $\mathrm{Na}+\mathrm{K}(+-)$ ATPase activity in individual wild brown trout ( Salmo trutta ). Journal of Experimental Biology 207 (3): 527-533.

Olesen, M. 2001. Sedimentation in Mariager Fjord, Denmark: the impact of sinking velocity on system productivity. Ophelia 55(1): 11-26.

Pedersen, S., Rassmussen G. and Manniche E. K. 1995. Limfjordens ørredbestande (II). IFF report nr. 45. Institut for Ferskvandsfiskeri og Fiskepleje (in Danish).

Stål, J., Pihl, L., and Wennhage, H. 2007. Food utilisation by coastal fish assemblages in rocky and soft bottoms on the Swedish west coast: Inference for identification of essential fish habitats. Estuarine, Coastal and Shelf Science 71(3): 593-607.

Svendsen, J.C., Eskesen, A.O., Aarestrup, K., Koed, A., and Jordan, A.D. 2007. Evidence for nonrandom spatial positioning of migrating smolts (Salmonidae) in a small lowland stream. Freshwater Biology 52(6): 1147-1158.

Thorstad, E.B., $\varnothing$ kland, F., Finstad, B., Sivertsgård, R., Plantalech, N., Bjørn, P.A., and McKinley, R.S. 2007. Fjord migration and survival of wild and hatchery-reared Atlantic salmon and wild brown trout post-smolts. Developments in Fish Telemetry: 99-107. 
Thorstad, E., Whoriskey, F., Uglem, I., Moore, A., Rikardsen, A., and Finstad, B. 2012. A critical life stage of the Atlantic salmon Salmo salar: behaviour and survival during the smolt and initial post-smolt migration. Journal of Fish Biology 81(2): 500-542.

Veinott, G., Westley, P.A., Warner, L., and Purchase, C.F. 2012. Assigning origins in a potentially mixed-stock recreational sea trout (Salmo trutta) fishery. Ecology of Freshwater Fish 21(4): 541551.

Wysujack, K., Greenberg, L., Bergman, E., and Olsson, I. 2009. The role of the environment in partial migration: food availability affects the adoption of a migratory tactic in brown trout Salmo trutta. Ecology of Freshwater Fish 18(1): 52-59.

\section{Figures:}




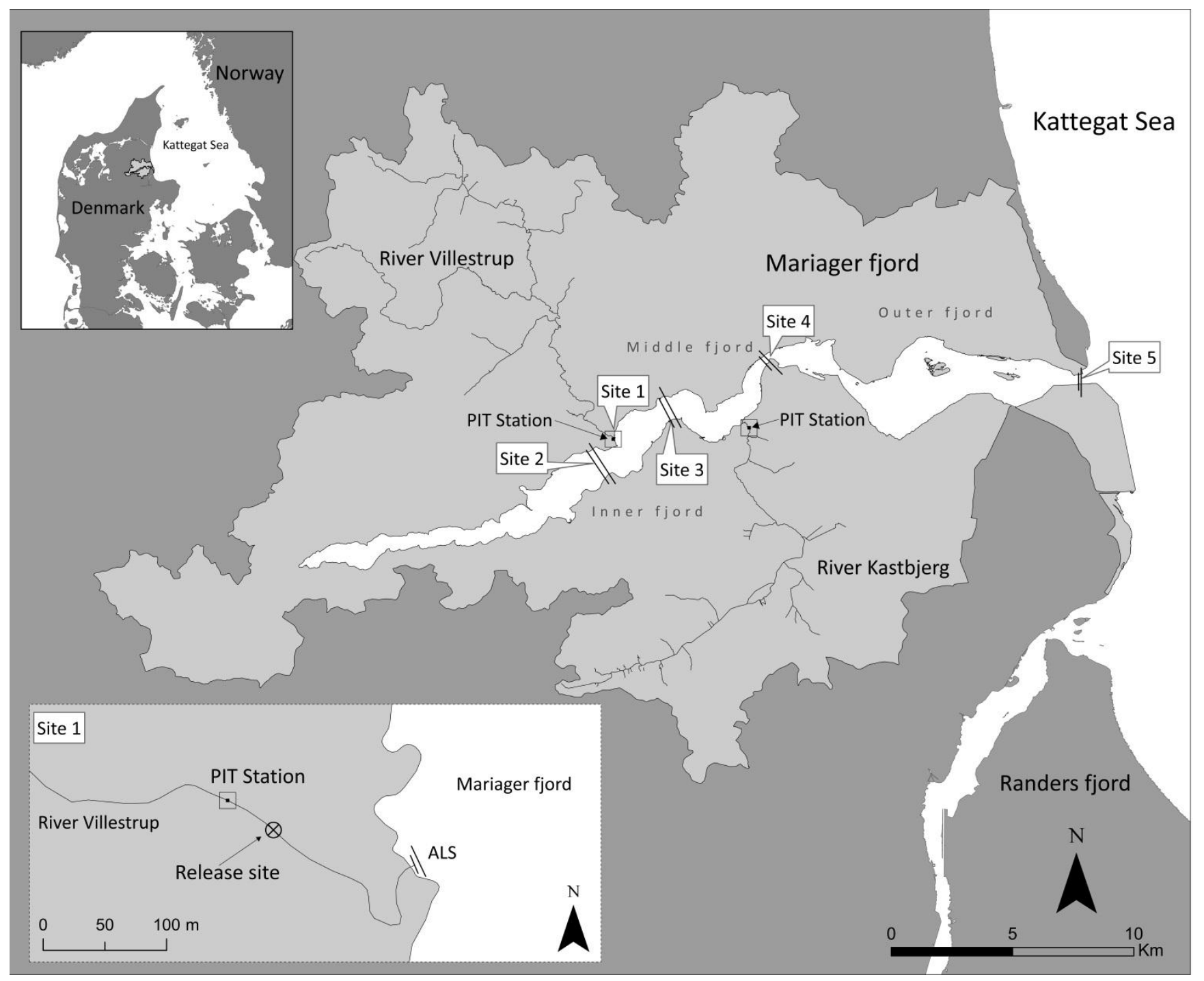

Fig. 1: The Mariager Fjord system in the east coast of Denmark with the capture and release site (site 1) for acoustic and PIT-tagged sea trout smolts. The fjord is divided in three different parts by the acoustic listening stations (ALS): the Inner fjord (from origin to site 3), the Middle fjord (between site 3 and 4) and the Outer fjord (between site 4 and 5). The ALS deployed in site 5 were moored at the outlet of the Fjord. 
Table 1: Morphological characteristics of the acoustic and PIT tagged smolts at the different tagging periods.

\begin{tabular}{|c|c|c|c|c|}
\hline & \multicolumn{2}{|c|}{2008} & \multicolumn{2}{|c|}{2009} \\
\hline & $\begin{array}{l}\text { April } \\
(n=40)\end{array}$ & $\begin{array}{l}\text { May } \\
(n=39)\end{array}$ & $\begin{array}{l}\text { April } \\
(n=40)\end{array}$ & $\begin{array}{l}\text { May } \\
(\mathrm{n}=40)\end{array}$ \\
\hline & \multicolumn{4}{|c|}{ mean $\pm \mathrm{sd}$} \\
\hline Length $(\mathrm{cm})$ & $17.4 \pm 1.1$ & $17.7 \pm 1.5$ & $18.0 \pm 1.6$ & $16.92 \pm 1.2$ \\
\hline Weight (g) & $45.7 \pm 10.1$ & $47.1 \pm 13.1$ & $53.57 \pm 14.9$ & $41.6 \pm 9.5$ \\
\hline Fulton's K & $0.86 \pm 0.035$ & $0.83 \pm 0.054$ & $0.89 \pm 0.051$ & $0.84 \pm 0.041$ \\
\hline
\end{tabular}

Table 2: Number of post-smolts which entered, stayed or migrated to sea th the different tagging periods.

Information on the fate and survival of the post-smolts is also provided. The number of FR and SM returning to the river correspond to the number of fish registered at the Pit-tag antennas as of September 2012.

\begin{tabular}{|c|c|c|c|c|c|c|c|}
\hline \multirow[b]{2}{*}{ Category } & \multicolumn{3}{|c|}{2008} & \multicolumn{3}{|c|}{2009} & \multirow[b]{2}{*}{ Overall } \\
\hline & April & May & Total & April & May & Total & \\
\hline Tagged & 40 & 39 & 79 & 40 & 40 & 80 & 159 \\
\hline Entered the fjord & 40 & 33 & 73 & 36 & 35 & 71 & 144 \\
\hline Stayed in the fjord (FR) & 18 & 16 & 34 & 18 & 15 & 33 & 67 \\
\hline Migrated to sea (SM) & 22 & 17 & 39 & 18 & 20 & 38 & 77 \\
\hline FR returned to river & 1 & 1 & 2 & 4 & 3 & 7 & 9 \\
\hline SM returned to river & 0 & 0 & 0 & 0 & 0 & 0 & 0 \\
\hline Intital Survival & $\begin{array}{c}23 \\
(57.5 \%)\end{array}$ & $\begin{array}{c}28 \\
(84.8 \%)\end{array}$ & $\begin{array}{c}51 \\
(69.9 \%)\end{array}$ & $\begin{array}{c}23 \\
(63.8 \%)\end{array}$ & $\begin{array}{c}32 \\
(91.4 \%)\end{array}$ & $\begin{array}{c}55 \\
(77.5 \%)\end{array}$ & $\begin{array}{c}106 \\
(73.6 \%)\end{array}$ \\
\hline
\end{tabular}




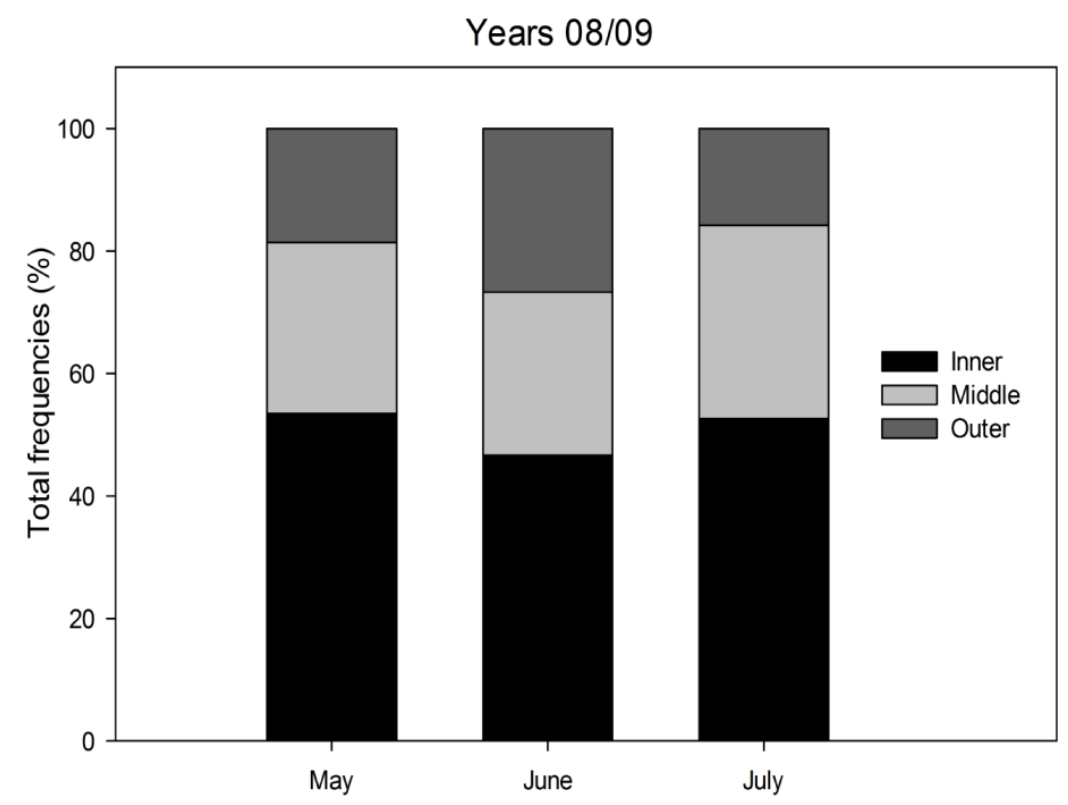

Fig. 2: Fjord habitat used by fjord resident post-smolts between the months May to July. The total individual registrations (frequencies) at each of the fjord sections (Inner, middle and outer) are displayed. Data for the years 2008 and 2009 is pooled. 